\title{
A New Structure of Geotextile Called Soil Nets for Reinforcement
}

\author{
Bo-Bo Xiong, ${ }^{1}$ Bin Tian, ${ }^{2}$ Xiao-chun Lu, ${ }^{2}$ and Bo-Fu Chen ${ }^{1}$ \\ ${ }^{1}$ College of Water Conservancy and Hydropower Engineering, Hohai University, Xi-Kang Road No. 1, Nanjing, Jiangsu 210098, China \\ ${ }^{2}$ College of Hydraulic and Environmental Engineering, Three Gorges University, Yichang, China
}

Correspondence should be addressed to Bo-Bo Xiong; zbqxbb19870@126.com

Received 4 May 2017; Accepted 13 August 2017; Published 18 September 2017

Academic Editor: Carlo Santulli

Copyright (C) 2017 Bo-Bo Xiong et al. This is an open access article distributed under the Creative Commons Attribution License, which permits unrestricted use, distribution, and reproduction in any medium, provided the original work is properly cited.

This paper proposes a new reinforcement structure called soil nets firstly, which is capable of strengthening foundations, slopes, and other structures with better effect than that of soilbags. This proposed geotextile structure typically contains several layers of soil net, which are placed in a unique way. One layer of soil net can be described as a collection of spherical soilbags that are connected together in two directions, one in which they are connected by ropes and another in which they are connected by the PP woven bags that contain the soil. A mechanical property analysis of the soil nets shows that the yield stress of the soil within the soil nets is improved, the tensile capacity of the soil nets is greater than that of the soil with which it is filled, and the equivalent coefficient of interlayer friction between the connected soil nets is larger than that for soilbags. Applications of this new reinforcement structure in the reinforcement of a foundation and a slope are considered, and the corresponding reinforcement effects are calculated. The calculation results demonstrate that the soil nets concept yields efficient reinforcement structures with many advantages.

\section{Introduction}

Many projects around the world require foundation reinforcement or slope treatment. In an effort to solve these problems, many methods have been proposed and put into practice, among which methods involving soilbags have been undergoing rapid development and attracting the interest of an increasing number of researchers over the past ten years.

Soilbags, which are fabricated from geotextiles and are filled with soil or soil-like materials [1], have long been used in flood control and as temporary retaining walls [2]. However, in the past decade, research on soilbags has revealed that soilbags have many advantages. Theoretical derivation proves that soilbags have greater ultimate compressive strength $[3,4]$. Experimental study indicated that soilbags have good durability in an environment without ultraviolet irradiation and with excellent freeze-thaw resistance $[1,5-$ 7]. Finite element method was adopted for analysing the behaviour of soilbags and the results have shown that soilbags can offer high bearing capacity and potentially beneficial damping effects [8-11]. By virtue of these excellent performance characteristics and their advantages of low cost, environmental friendliness, and simple technology, soilbags have been widely used in many project fields $[1,2,4-7$, 12-18]. However, it has been found that the connections among an aggregation of soilbags are weak, thereby limiting their mechanical properties. In addition, the manufacture of soilbags is time-consuming, which affects their popular acceptance and application. Thus, a new, optimal soilbag design is required to overcome these deficits, which serves as the primary motivation for this research.

In this paper, a new structure called soil nets for reinforcement is introduced. The proposed soil nets structure not only possesses the same advantages offered by soilbags but also overcomes the deficiencies of soilbags discussed above. The proposed structure consists of several soil net layers; the exact number of soli net layers is determined by the specific stabilization requirements of the application. As shown in Figure 1, one soil net layer can be described as an aggregation of spherical soilbags that are connected together in two directions, one in which they are connected by ropes and another in which they are connected by the polypropylene (abbreviated as PP) woven bags that contain the soil. This mode of connection allows the soil net structure as a whole 


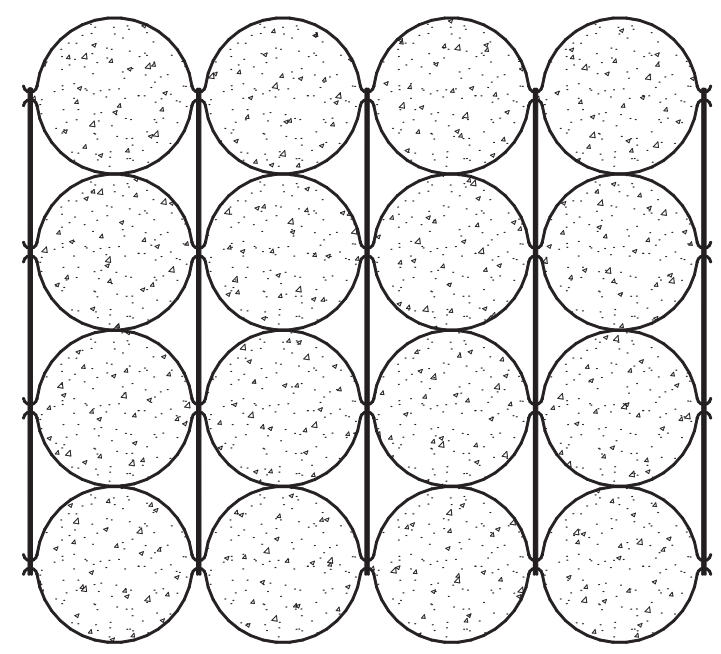

FIGURE 1: Structural scheme of one soil net layer.

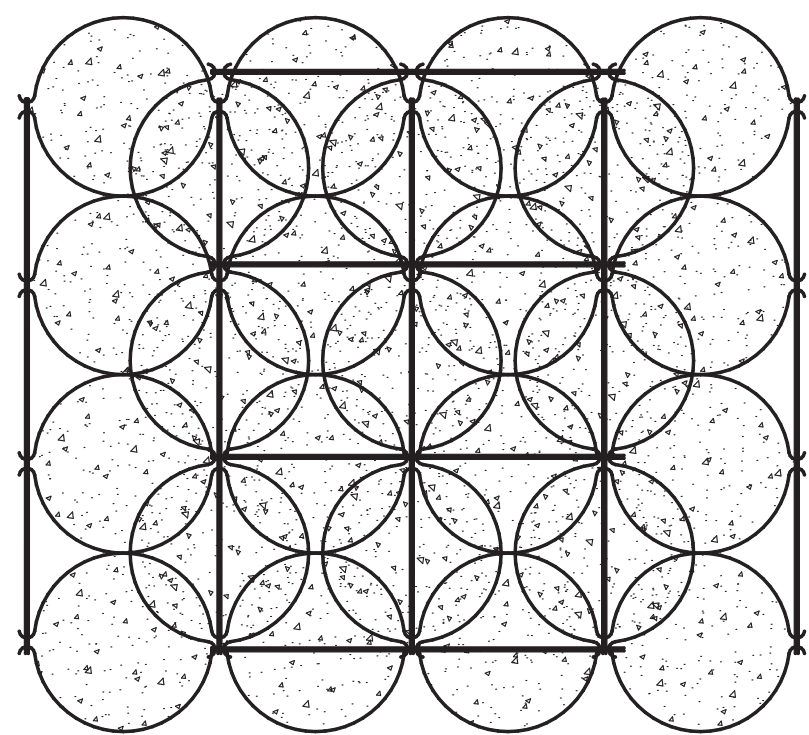

(a)

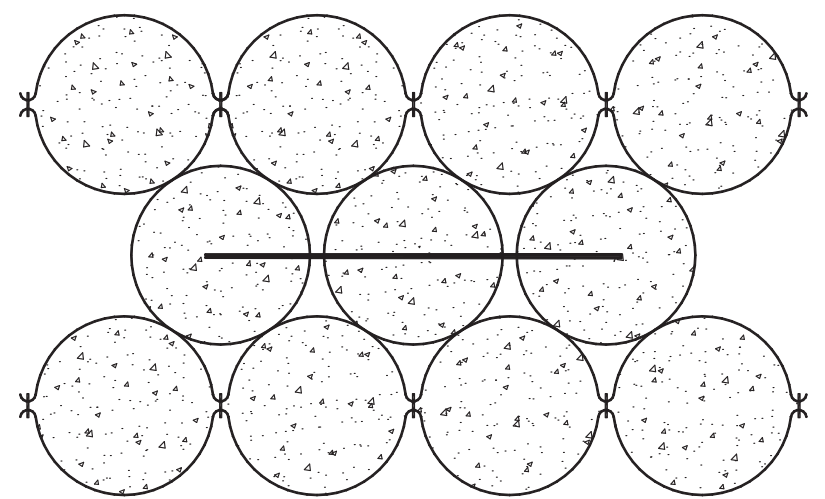

(b)

FIgURE 2: Structural scheme of multiple soil net layer, (a) top view and (b) front view.

to exhibit better mechanical properties. As illustrated in Figure 2, adjacent soil net layers are placed such that every spherical soilbag in the upper soil net layer is embedded in the centre of the four contiguous spherical soilbags below, thereby guaranteeing a relatively large equivalent coefficient of interlayer friction between adjacent soil net layers. Moreover, it can be observed in Figure 1 that one long soilbag section that is tied with rope at equal distances can form many spherical soilbags, enabling the formation of a large number of spherical soilbags once the long PP woven bags have been filled with soil; therefore, the construction of the soil net layers is amenable to mechanization. An application of the soil nets concept, involving the reinforcement of a foundation and a slope, is considered in this paper. The calculation results demonstrate that the soil nets structure offers reasonably effective reinforcement. Therefore, the soil nets proposal represents a type of reinforcement structure with many merits and excellent potential for widespread adoption.

\section{The Soil Nets Structure}

This paper presents a new structure called soil nets, which is more effective than soilbags at increasing the bearing capacity of a foundation or the stability of a slope or a retaining wall. In the following paragraphs, the soil nets structure will be introduced in detail.

As shown in Figure 1, one soil net layer primarily consists of several long soilbag sections, which differ from the traditional soilbag. This type of long soilbag is actually a long PP woven bag filled with soil that is tied with ropes at equal distances to form many interconnected spherical 
soilbags. Multiple long soilbags of this kind are placed closely together in a parallel arrangement and then connected by ropes at each row of knots, as shown in Figure 1. The ropes used to partition the PP woven bags and to connect the long soilbags are made of the same material as the bags. A single soil net layer can also be regarded as a collection of spherical soilbags connected together in two directions, one in which they are connected by ropes and another in which they are connected by the soilbags themselves. This integrated structure endows the soil nets concept with great efficiency for foundation reinforcement or slope consolidation. The strengthening principle of the soil nets structure will be introduced in detail later.

In many cases, one soil net layer is not sufficient. The method used for the placement of multiple soil net layers, which is illustrated in Figure 2, is one of the important characteristics of the soil nets concept. Every soil net layer is placed on top of another soil net layer, and every spherical soilbag in the upper layer is embedded in the centre of the four contiguous soilbags below. As a result, the proposed soil nets structure not only reduces interlayer sliding between contiguous soil net layers but also makes full use of the strength of the PP woven bags. This interaction mechanism will be discussed in the next section of this paper. In addition, to ensure the stability and uniformity of the soil nets structure, each soil net layer should alternate in direction, as shown in Figure 2(b).

The dimensions of the proposed unique soilbags are determined in accordance with the conditions of the soil with which they are to be filled and the nature of the reinforcement project. However, the diameter of the soilbags should not exceed 0.5 meters because a larger soilbag diameter implies a less relative amount of the woven PP material in the structure, which is essential to the reinforcement effect.

The difficulty of implementing a particular technology can strongly affect the extent of its application. However, to soil nets structure, a single long soilbag section contains many interconnected spherical soilbags, and once filled, a long PP woven bag can be formed into many spherical soilbags. The process of filling the long PP woven bags can be rapidly accomplished using machines, thereby overcoming one disadvantage of traditional soilbags. From this perspective, the soil nets structure can be efficiently constructed for a strengthening application, saving manpower and time.

\section{Mechanical Properties of Soil Nets}

\subsection{Analysis of an Individual Spherical Soilbag. A soil net layer} can be regarded as a collection of interconnected spherical soilbags; thus, it is first necessary to analyse the physical characteristics of a single spherical soilbag. Because of the presence of the PP woven bag, the strength of such a spherical soilbag is considerably greater than that of a comparable volume of soil that is not wrapped in a PP woven bag. The improvement in strength of such a soilbag can be primarily attributed to the tensile force along the PP woven bag that develops as a result of the extension of the perimeter of the bag when it is under load. In addition, such a tensile force can also emerge when the soil filling the bag develops a swelling

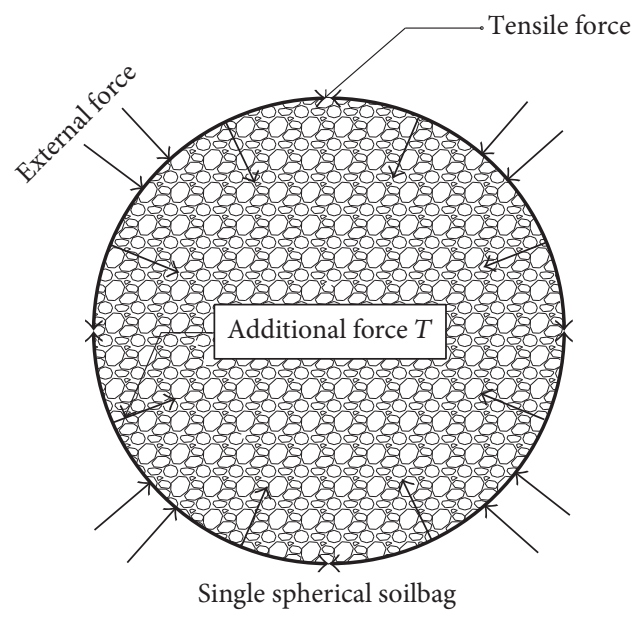

FIgURE 3: Schematic view of the forces acting on a spherical soilbag.

deformation due to wetting or shear dilation. This tensile force produces an additional force $T$ on the soil particles inside the bag, and this additional force $T$ can constrain the lateral deformation of the soil particles, thereby acting as a confining pressure. A schematic view of these forces is displayed in Figure 3. Meanwhile, this additional force $T$ along the PP woven bag enhances the contacts between the soil particles inside, leading to an increase in the normal contact force $N$ and consequently enhancing the frictional force $F$ between the soil particles [ 4 ] $(F=\mu * N$, where $\mu$ is the coefficient of friction). Therefore, a spherical soilbag exhibits high strength.

Matsuoka and Liu [14] derived a strength formula for a traditional soilbag based on the Mohr-Coulomb theory. However, this strength formula does not consider the effect of the intermediate principal stress, and the failure surface defined by this theory is not smooth, thereby introducing inaccuracy and inconvenience into the application of the associated flow rule and related numerical analyses. In this paper, a strength formula is presented for a single spherical soilbag based on the Drucker-Prager criterion. To simplify the derivation procedure, a single spherical soilbag is regarded as a sphere under the action of an external load; although not strictly accurate, this simplification will not considerably affect the loading situation of the majority of the soil particles inside the bag. Figure 3 also serves as an illustration of the loading situation of the PP woven bag and the soil particles inside. Under the action of an external load, the principal stresses on the soil within the bag are $\sigma_{o 1}, \sigma_{o 2}$, and $\sigma_{o 3}$ (where the subscript $o$ indicates the stress caused by the external load). Furthermore, the external load and the swelling of the soil within the PP woven bag also cause the PP woven bag stretch and a tensile force develops along the PP woven bag, which induces an additional stress on the soil within; these additional principal stresses are $\sigma_{t 1}, \sigma_{t 2}$, and $\sigma_{t 3}$ (where the subscript $t$ indicates the stress caused by the additional force $T$ ). The tensile stress on the PP woven bag caused by the external force is denoted by $\sigma_{t t}$, and this tensile stress $\sigma_{t t}$ is assumed to be equal in all directions 
( $\sigma_{t t} \leq \sigma_{t f}$, where $\sigma_{t f}$ is the ultimate tensile strength of the polypropylene). Based on the force equilibrium of the soil inside the bag, the additional principal stresses $\sigma_{t 1}, \sigma_{t 2}$, and $\sigma_{t 3}$ can be calculated as follows:

$$
\sigma_{t 1}=\sigma_{t 2}=\sigma_{t 3}=\frac{h \cdot 2 \cdot \pi \cdot r \cdot \sigma_{t t}}{\pi \cdot r^{2}}=\frac{2 \cdot h \cdot \sigma_{t t}}{r},
$$

where $h$ is the thickness of the PP woven bag and $r$ is the radius of a single spherical soilbag. Eq. (1) shows that when the PP woven bag is thicker or possesses a greater ultimate tensile strength or when the soilbag radius is smaller, the soil inside the bag can be subjected to greater additional stress.

Based on the Drucker-Prager criterion, the yield criterion for a spherical volume of soil wrapped in a PP woven bag can be obtained by combining

$$
\begin{aligned}
& F=\alpha I_{1}+\sqrt{J_{2}}-k \\
& \alpha=\frac{2 \sin \varphi}{\sqrt{3}(3-\sin \varphi)} \\
& k=\frac{6 c \cos \varphi}{\sqrt{3}(3-\sin \varphi)},
\end{aligned}
$$

where $I_{1}$ is the first invariant of the stress tensor, $J_{2}$ is the second invariant of the stress deviator, $c$ is the cohesion of the soil inside the PP woven bag, and $\varphi$ is the friction angle of the soil inside the PP woven bag. Because the additional stresses $\sigma_{t 1}, \sigma_{t 2}$, and $\sigma_{t 3}$ are compressive stresses, they appear as $-\sigma_{t 1}$, $-\sigma_{t 2}$, and $-\sigma_{t 3}$ in (5):

$$
\begin{aligned}
& I_{1}=\left(\sigma_{o 1}-\sigma_{t 1}\right)+\left(\sigma_{o 2}-\sigma_{t 2}\right)+\left(\sigma_{o 3}-\sigma_{t 3}\right) \\
& J_{2}=\frac{1}{6}\left[\left(\sigma_{o 1}-\sigma_{o 2}\right)^{2}+\left(\sigma_{o 2}-\sigma_{o 3}\right)^{2}+\left(\sigma_{o 3}-\sigma_{o 1}\right)^{2}\right] .
\end{aligned}
$$

By inserting (5) into (2), the yield criterion for a spherical volume of soil wrapped in a PP woven bag can be rewritten as

$$
\begin{gathered}
F=\alpha I_{1}+\sqrt{J_{2}}-k-\alpha\left(\sigma_{t 1}+\sigma_{t 2}+\sigma_{t 3}\right) \\
k_{\mathrm{bag}}=k+\alpha\left(\sigma_{t 1}+\sigma_{t 2}+\sigma_{t 3}\right)=k+\frac{6 \alpha h \sigma_{t t}}{r} .
\end{gathered}
$$

Eq. (8) illustrates that the material constant of the soil within the PP woven bag, $k_{\mathrm{bag}}$, consists of two components: the intrinsic material constant of the soil, $k$, and the additional material constant calculated as $6 \alpha h \sigma_{t t} / r$. Thus, soil within a $\mathrm{PP}$ woven bag has a greater yield stress than a comparable volume of unwrapped soil, as shown in Figure 4. Furthermore, the cohesion of the soil within the PP woven bag can also be considered to have increased from $c$ to $c+2 h \sigma_{t t} \tan \varphi / r$ (derived from (2), (3), (4), (5), and (7)).

To illustrate this compression capacity, a simple example is considered below. The general values of the physical parameters of a PP woven bag are as follows: the ultimate tensile strength of the bag, $\sigma_{t f}$, is $100 \mathrm{MPa}$, and it is assumed that $\sigma_{t t}=\sigma_{t f}=100 \mathrm{MPa}$; the radius of a single spherical soilbag, $r$, is $0.25 \mathrm{~m}$; and the thickness of the bag, $h$, is $0.1 \mathrm{~mm}$.

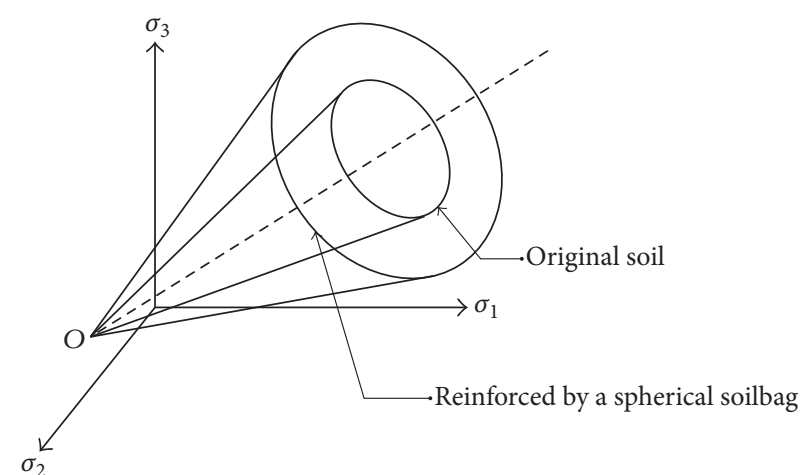

FIGURE 4: Yield surface of a spherical volume of soil reinforced by a $\mathrm{PP}$ woven bag.

The soil filling the PP woven bag has a cohesion of $c=1 \mathrm{KPa}$ and a friction angle of $\varphi=40^{\circ}$ [8]. The intrinsic material constant of the soil, $k$, is $1125.76 \mathrm{~Pa}$, as obtained from (4), and the material constant of the soil within the PP woven bag is $k_{\text {bag }}=75569.99 \mathrm{~Pa}$, as calculated using (1) and (8). The material constant of the soil has multiplied 68 times, because of the PP woven bag. Furthermore, (1) reveals that with a greater thickness of the PP woven bag and a smaller soilbag radius, the material constant will be further increased.

Based on the strengthening principle and the concrete example of a single spherical soilbag described above, either an external load or a swelling of the soil within the PP woven bag can induce additional stress in the PP woven bag, thereby considerably increasing the strength of the soil within the bag. However, if $\sigma_{t t}$ exceeds $\sigma_{t f}$, then the bag will be damaged and lose its compression capacity, which should be taken into attention in application.

3.2. Analysis of One Soil Net Layer. As shown in Figure 1, one soil net layer can be regarded not only as a collection of spherical soilbags connected together in two directions but also as a net with a soilbag at each grid intersection. The above analysis has proven that a single spherical soilbag exhibits a high strength. Proceeding from this analysis, it is necessary to study the mechanical properties of the soil net layer as a whole. The stress characteristics of a single soil net layer are similar to those of a rope net, and the tensile capacity of such a soil net layer is the main focus of the analysis presented in this section.

Generally speaking, the tensile stress of common soil is quite low, varying from several to several tens of $\mathrm{kPa}$. Earth structures are often damaged because of this low tensile stress. However, the proposed soil nets structure has a relatively high tensile capacity. Figure 1 illustrates that the pulling forces in an soil net layer are sustained by the PP woven bags in one direction and by the connecting ropes in the other direction. Because the tensile strength of the connecting ropes is easy to calculate and control, only the equivalent ultimate tensile strength in the direction connected by the PP woven bags is derived below (the tensile strength of the soil itself is not 


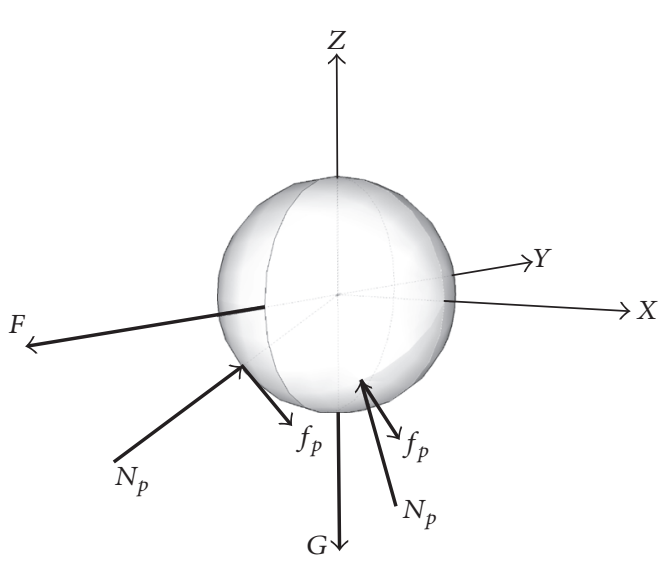

(a)

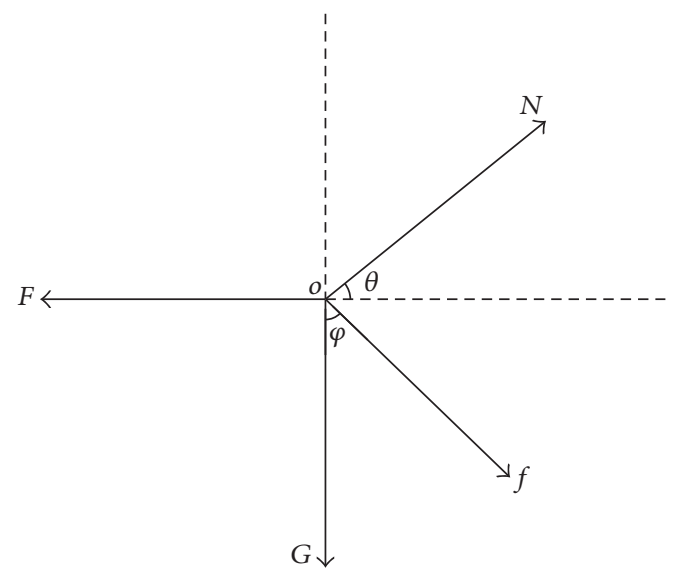

(b)

Figure 5: Force analysis of a single spherical soilbag. (a) Three-dimensional graph, Force analysis of a single spherical soilbag. (b) Planar graph.

considered because it is relatively small compared with that of the PP woven bag):

$$
\sigma_{o t}=\frac{F}{S}
$$

where $\sigma_{o t}$ is the equivalent ultimate tensile strength of the soil net structure, $F$ is the pulling force sustained by the PP woven bags, and $S$ is the equivalent cross-sectional area of the soil net layer. $F$ and $S$ can be obtained from

$$
\begin{aligned}
& F=n \cdot 2 \cdot \pi \cdot r \cdot h \cdot \sigma_{t f} \\
& s=n \cdot 2 \cdot r \cdot 2 \cdot r \cdot \cos 30^{\circ},
\end{aligned}
$$

where $r, h$, and $\sigma_{t f}$ have the same definitions as above and $n$ is the number of spherical soilbags subjected to the pulling force. Therefore, (9) can be rewritten as follows:

$$
\sigma_{o t}=\frac{F}{S}=\frac{\pi \cdot h \cdot \sigma_{t f}}{2 \cdot r \cdot \cos 30^{\circ}} .
$$

To illustrate the equivalent ultimate tensile strength of a soil net layer, a simple example is considered below. Using the same physical parameter values as before for the PP woven bags, the equivalent ultimate tensile strength of the soil net layer, $\sigma_{o t}$, is calculated to be $72.5 \mathrm{kPa}$ using (11). This result demonstrates that because of the PP woven bags, the equivalent ultimate tensile strength of the soil nets structure is several times greater than that of common soil, indicating that when serving as a reinforcement material, the soil nets structure exhibits a relatively high equivalent ultimate tensile strength.

3.3. Analysis of Multiple Soil Net Layers. The slip resistance between different soil net layers is studied in this section. Because of the unit placement scheme in the proposed soil nets structure, the interlayer gliding of the soil net layers is quite different from the planar failure surface of traditional soilbags. As shown in Figure 2, every spherical soilbag is embedded in the centre of the four contiguous spherical soilbags below, which means that it is not easy for sliding to occur between different soil net layers.

To evaluate this interlayer gliding, an equivalent coefficient of the interlayer friction between soil net layers, $\mu_{\mathrm{eq}}$, is defined:

$$
\mu_{\mathrm{eq}}=\frac{F}{G}
$$

where $F$ and $G$ are the horizontal and vertical forces induced by the gravity of the single soilbag itself and the pressure of the soilbags above, respectively. The free-body diagram of a single spherical soilbag is presented in Figure 5. By analysing its stress state, the force equilibrium equations, (13), can be established.

$$
\begin{aligned}
F & =N \cdot \cos \theta+f \cdot \sin \varphi \\
N \cdot \sin \theta & =G+f \cdot \cos \varphi,
\end{aligned}
$$

where $\theta$ is the angle between $N$ and the horizontal plane and $\varphi$ is the angle between $f$ and the vertical plane. $f$ is the frictional force, which can be written as in (14), and $N$ is the resulting supporting force, which can be expressed as in (15).

$$
\begin{aligned}
& f=2 \cdot N_{p} \cdot \mu \\
& N=2 \cdot N_{p} \cdot \cos \frac{\alpha}{2},
\end{aligned}
$$

where $N_{p}, \mu$, and $\alpha$ are the supporting force, the friction coefficient of a PP woven bag, and the angle between two supporting forces $N_{p}$, respectively. Thus, by incorporating the information from (13), (14), and (15), (12) can be rewritten as

$$
\mu_{\mathrm{eq}}=\frac{\cos (\alpha / 2) \cdot \cos \theta+\mu \cdot \sin \varphi}{\cos (\alpha / 2) \cdot \sin \theta-\mu \cdot \cos \varphi} .
$$

According to the geometrical positions of the soilbags in the soil net structure as displayed in Figure 2, it can be found 


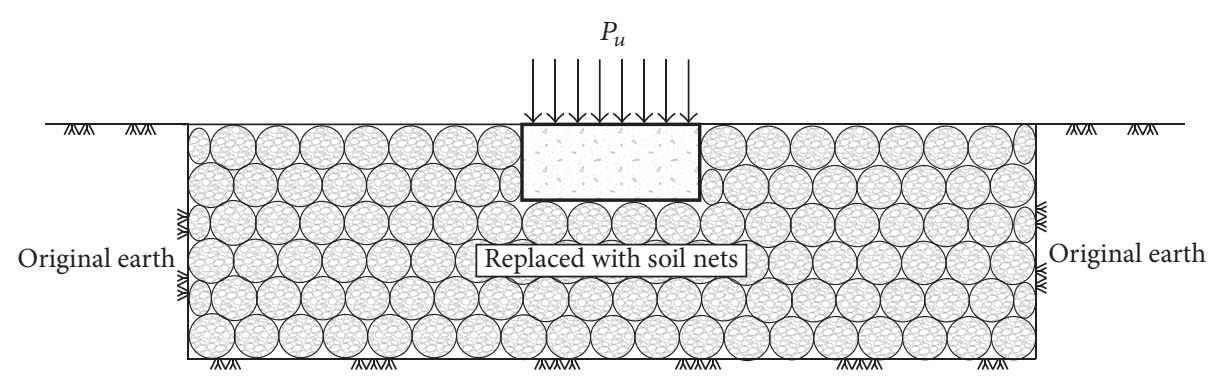

FIGURE 6: Schematic diagram of a foundation with soil nets reinforcement.

that $\theta+\varphi=90^{\circ}, \theta=45^{\circ}$, and $\alpha \approx 70.53^{\circ}$, when potential asymmetric deformations of the soilbags are neglected. Generally, the friction coefficient of a PP woven bag, $\mu$, is 0.3 [4]; thus, the equivalent coefficient of interlayer friction between soil net layers, $\mu_{\mathrm{eq}}$, is 2.16 , as calculated from (12). The value of $\mu_{\mathrm{eq}}$ is 7.2 times greater than that of $\mu$, thereby confirming that the soil net structure offers good interlayer gliding resistance.

\section{Application}

4.1. Reinforcement of a Foundation Using the Soil Nets Concept. The bearing capacity of the foundation is one of the most important factors in determining the safety of most kinds of buildings. Therefore, many foundation reinforcement methods have been developed and applied, and, for this purpose, soilbags have been used to good effect in recent years. The soil nets structure proposed in this paper can also be used for such reinforcement projects, and the structure's performance in this context will be analysed below.

Figure 6 is a simple schematic diagram of a foundation with soil nets reinforcement. First, the excavation for the foundation is performed, and the soil nets structure is then laid into the foundation pit under roller compaction in a layer-by-layer manner. The soil from the excavation or other building waste is suitable material for filling the PP woven bags used to form the structure, meaning that this reinforcement method requires relatively little investment and is also environmentally friendly. As a result of the large gaps between the spherical soilbags, water can be rapidly excreted from the foundation; in other words, a foundation reinforced using the soil nets concept is not appreciably affected by either rainwater or groundwater.

In the example considered here, the foundation has a width of $2 \mathrm{~m}$ and a buried depth of $1 \mathrm{~m}$, and the parameters of the PP woven bags and the soil used to fill them are the same as in the previous example calculations. The ultimate bearing capacities of the foundation with and without soil nets reinforcement can be calculated based on the Terzaghi bearing capacity formula, as shown in (11).

$$
P_{u}=c \cdot N_{c}+\gamma \cdot d \cdot N_{q}+\frac{1}{2} \cdot \gamma \cdot b \cdot N_{r}
$$

where $c$ is the cohesion of the foundation soil; $\gamma$ is the density of the bulk soil; $b$ is the width of the building; $d$ is the buried depth of the building; and $N_{c}, N_{q}$, and $N_{r}$ are the bearing capacity factors. Using the above parameters and (11), the ultimate bearing capacities of the foundation with and without soil nets reinforcement can be found to be $79.6 \mathrm{kPa}$ and $722.7 \mathrm{kPa}$, respectively. This result confirms the excellent effectiveness of the soil nets structure as a method of ground reinforcement.

4.2. Stability Analysis of a Slope Reinforced Using the Soil Nets Concept. Slope failure is one of the most common geological hazards that pose a risk of great harm to people's lives and property; therefore, slope reinforcement is a significant scientific and engineering problem that has drawn considerable attention. The proposed soil nets concept is an excellent slope reinforcement structure, especially for soil slopes. This slope reinforcement structure offers various advantages, such as environmental friendliness, a low investment cost, an excellent reinforcement effect, high frost resistance, excellent antierosion properties, and good durability. The effectiveness of soil nets reinforcement in such applications is clearly illustrated by the example below.

Figure 7 shows a typical soil slope treated using the proposed soil nets concept, which has a height of $20 \mathrm{~m}$ and a gradient of $1: 1.5$. The soil nets reinforcement structure consists of 4 soil net layers, which are placed on the surface of the slope. Assume that the location of the sliding surface in Figure 7 is indicated by the slip denoted by BCD and that the distance between the departure point $B$ and the slope top A is $8.3 \mathrm{~m}$. Thus, it can be calculated that the radius $R$ of the sliding surface is $50.6 \mathrm{~m}$. For convenience of calculation, assume that the thickness of the slope is $1 \mathrm{~m}$. The soil on the treated slope has a cohesion of $c=18.6 \mathrm{kPa}$, friction angle of $\varphi=27.3$, and the density of $1.92 \mathrm{~g} / \mathrm{cm} 3$ [1], what is more, the soil used to fill the PP woven bags was taken from the surface of the slope. The ultimate tensile strength of the PP woven bag, $\sigma_{t f}$, is $100 \mathrm{MPa}$; the radius of a single spherical soilbag, $r$, is $0.25 \mathrm{~m}$; and the thickness of the PP woven bags, $h$, is $0.1 \mathrm{~mm}$ [8].

The forces acting on the soil nets assembly and the underlying soil of the slope can be analysed to calculate the safety factor as shown in Figure 8. According to the Swedish method of slices, the safety factor $F_{s}$ can be calculated as follows:

$$
F_{s}=\frac{f_{1}+\sum c_{i} \cdot l_{i}+W_{i} \cdot \cos \alpha_{i} \cdot \tan \varphi}{\sum W_{i} \cdot \sin \alpha_{i}},
$$

where $f_{1}$ is the antisliding force that is generated along the soil nets structure, $c_{i}$ is the cohesion of the slope soil, $l_{i}$ is 


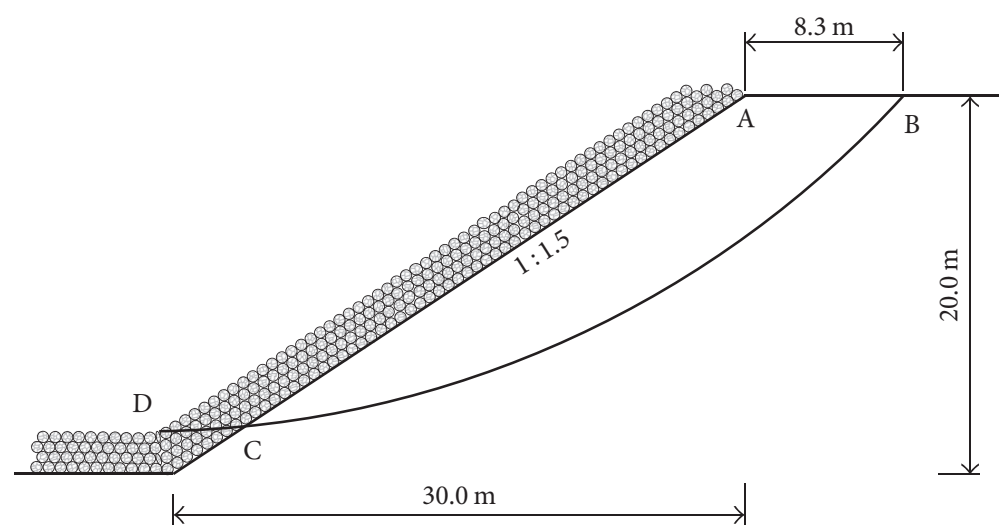

FIGURE 7: Schematic diagram of a slope with soil nets reinforcement.

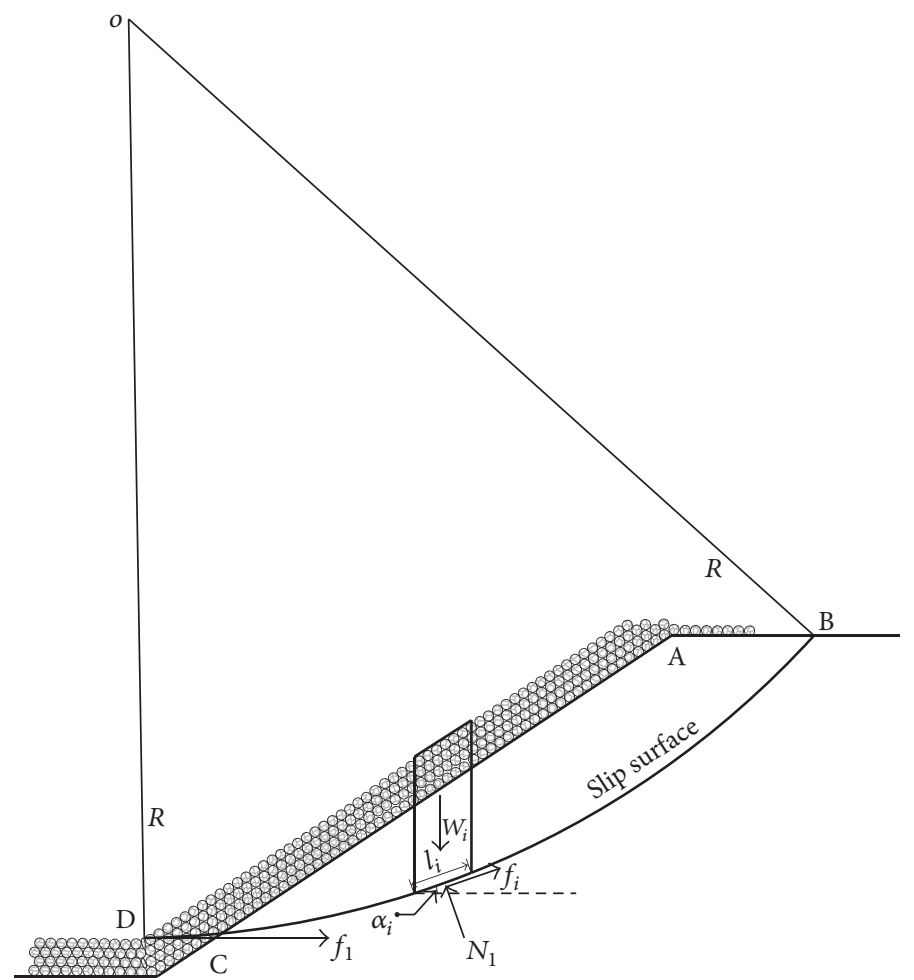

FIGURE 8: Forces acting on the soil nets structure and the underlying slope.

the length of each soil slice, $W_{i}$ is the weight of each soil slice (where the slices of divided soil include the soil nets structure placed on the slope), and $\alpha_{i}$ is the angle between the bottom of each soil slice and the horizontal plane.

An analysis of the soil nets assembly to determine the value of $f_{1}$ reveals that when the 4 soil net layers experience tensile failure, $f_{1}$ reaches its limiting value. If the reinforcing soil nets structure is not too thick compared with the dimensions of the slope, $f_{1}$ can always reach this limiting value. According to the analysis presented above, the limiting value of $f_{1}$ can be calculated as follows:

$$
f_{1}=8 \cdot 2 \cdot \pi \cdot r \cdot h \cdot \sigma_{t f} .
$$

The safety factors of the slope with and without reinforcement are calculated to be 1.49 and 1.56, respectively. In addition, if the thickness of the PP woven bags is $1 \times 10^{-3} \mathrm{~m}$, then the safety factor of the slope will be increased to 2.19 . The proposed soil nets structure clearly exerts a very good reinforcement effect.

It is worth noting that, to simplify the calculation process, the stability analysis of the slope with soil nets reinforcement was performed using a two-dimensional model, which considers only the interlayer antisliding capability of the soil nets structure and ignores its high tensile capacity; thus, the calculated safety factor for soil nets-based slope reinforcement is a conservative result. 
As is well known, landslides are liable to occur in cases of heavy rain because the rainwater saturating the soil cannot be excreted sufficiently quickly, and as a result, both the effective stress and the material parameters of the soil decrease. However, the proposed soil nets structure can shed water quite rapidly by virtue of its unique structural characteristics, which means that the soil nets structure serving to provide slope reinforcement can protect the slope very well even under heavy rain.

\section{Conclusion}

To guarantee sufficient, environmentally friendly reinforcement for foundations, slopes, retaining wall, or other structures at an appropriate cost, a new reinforcement structure called soil nets was proposed and investigated in this paper for the first time. The soil nets structure consists of multiple soil net layers, each of which can be regarded as a collection of spherical soilbags. In this structure, many spherical soilbags are connected together in two directions, one in which they are connected by ropes and another in which they are connected by the PP woven bags themselves, to form each soil net layer, and multiple soil net layers are arranged such that every spherical soilbag in the upper soil net layer is embedded in the centre of the four contiguous spherical soilbags below. Rigorous mechanical analyses of a single spherical soilbag, a single soil net layer and multiple soil net layers were presented. It was found that the yield stress of the soil within the soil nets structure is improved by being wrapped in the $\mathrm{PP}$ woven bags, and because of the connections among the spherical soilbags, the tensile capacity of a soil net layer is also greater than that of a comparable volume of the soil with which it is filled. Moreover, the relative placement of the spherical soilbags results in a large equivalent coefficient of interlayer friction between soil net layers. Furthermore, the proposed soil nets structure also has the advantages of environmental friendliness, a low investment cost, high frost resistance, and excellent antierosion properties just as the traditional soilbag. Two case studies, involving the reinforcement of a foundation and a slope using the soil nets concept, were presented. The effects of soil nets reinforcement in these cases were calculated, and the results demonstrate that the proposed soil nets structure exhibits excellent reinforcement performance. Based on the above study, it can be reasonably concluded that the proposed soil nets structure demonstrates high potential for the reinforcement of foundations, slopes, or other structures. In future, further efforts will yet be needed to investigate the reinforcement effects of the soil nets concept in practice.

\section{Conflicts of Interest}

The authors declare that they have no conflicts of interest.

\section{Acknowledgments}

The current work was financially supported by National Natural Science Foundation of China (Grant no. 51509142). The
National Natural Science Foundation-Outstanding Youth Foundation supported this work under Grant no. 51509142. The authors would like to acknowledge Dr. Si-Hong Liu for his helpful discussions. The authors thank AJE for its linguistic assistance during the preparation of this manuscript.

\section{References}

[1] S.-H. Liu, J.-J. Gao, Y.-Q. Wang, and L.-P. Weng, "Experimental study on vibration reduction by using soilbags," Geotextiles and Geomembranes, vol. 42, pp. 52-62, 2014.

[2] G. L. Chen, Y. Huang, M. Sato, and S. Chida, "Application of stacked soilbags for slope protection," in Geosynthetics in Civil and Environmental Engineering, pp. 609-614, Springer, Berlin, Gemany, 2008.

[3] F. Bai, S. Liu, and Y. Wang, "Research on reinforcement mechanism and failure strength of soilbags," Yantu Lixue/rock and Soil Mechanics, vol. 31, no. 1, pp. 172-176, 2010.

[4] S. Liu, F. Bai, Y. Wang, S. Wang, and Z. Li, "Treatment for expansive soil channel slope with soilbags," Journal of Aerospace Engineering, vol. 26, no. 4, pp. 657-666, 2013.

[5] S. Liu, X. Xue, K. Fan, and S. Xu, "Earth pressure and deformation mode of a retaining wall constructed with soilbags," Yantu Gongcheng Xuebao/Chinese Journal of Geotechnical Engineering, vol. 36, no. 12, pp. 2267-2273, 2014.

[6] Y. Nakagawa, G. L. Chen, T. Tatsui, and S. Chida, "Verification of vibration reduction characteristics with soilbag structure," in Geosynthetics in Civil and Environmental Engineering, G. Li, Y. Chen, and X. Tang, Eds., pp. 603-608, Springer, Berlin, Germany, 2008.

[7] B. Niu, C. J. Zhang, X. L. Chen, and H. Y. Wang, "A semiAnalytical method to calculate the consolidation problem of the soilbag filled with mud soil buried with PVD," Applied Mechanics and Materials, vol. 638-640, pp. 345-349, 2014.

[8] Y. Ansari, R. Merifield, H. Yamamoto, and D. Sheng, "Numerical analysis of soilbags under compression and cyclic shear," Computers and Geotechnics, vol. 38, no. 5, pp. 659-668, 2011.

[9] E. Bauer and SF. Tantono, "Numerical simulation of a soilbag under vertical compression," in proceedings of the 12th International Conference on Computer Methods and Advances in Geomechanics, pp. 433-439, Goa, India, 2008.

[10] Y. Wang and L. Wang, "Numerical simulation of vibration reduction and energy dissipation of soilbags," Yantu Lixue/rock and Soil Mechanics, vol. 35, no. 2, pp. 601-606, 2014.

[11] Z. Li, S. Liu, L. Wang, and C. Zhang, "Experimental study on the effect of frost heave prevention using soilbags," Cold Regions Science and Technology, vol. 85, pp. 109-116, 2013.

[12] S. M. Lee, C. H. Choi, and E. C. Shin, "A study of connection stability for reinforced retaining wall constructed with soilbag with varying connection strength," Journal of the Korean Geosynthetics Society, vol. 12, no. 1, pp. 101-107, 2013.

[13] S. Liu, Y. Lu, L. Weng, and F. Bai, "Field study of treatment for expansive soil/rock channel slope with soilbags," Geotextiles and Geomembranes, vol. 43, no. 4, pp. 283-292, 2015.

[14] H. Matsuoka and S. Liu, "New Earth reinforcement method by soilbags (“donow")," Soils and Foundations, vol. 43, no. 6, pp. 173-188, 2003.

[15] E. C. Shin, M. S. Lee, and S. H. Kim, "Evaluation of PBD as horizontal drains of soilbag retaining wall," Journal of the Korean Geosynthetics Society, vol. 12, no. 2, pp. 35-42, 2013. 
[16] Y. F. Xu and J. Huang, "Case study on earth reinforcement using soilbags," in Geosynthetics in Civil and Environmental Engineering, G. Li, Y. Chen, and X. Tang, Eds., pp. 597-602, Springer, Berlin, Germany, 2008.

[17] Y. Xu, J. Huang, Y. Du, and D. Sun, "Earth reinforcement using soilbags," Geotextiles and Geomembranes, vol. 26, no. 3, pp. 279289, 2008.

[18] L.-J. Wang, S.-H. Liu, and B. Zhou, "Experimental study on the inclusion of soilbags in retaining walls constructed in expansive soils," Geotextiles and Geomembranes, vol. 43, no. 1, pp. 89-96, 2015. 

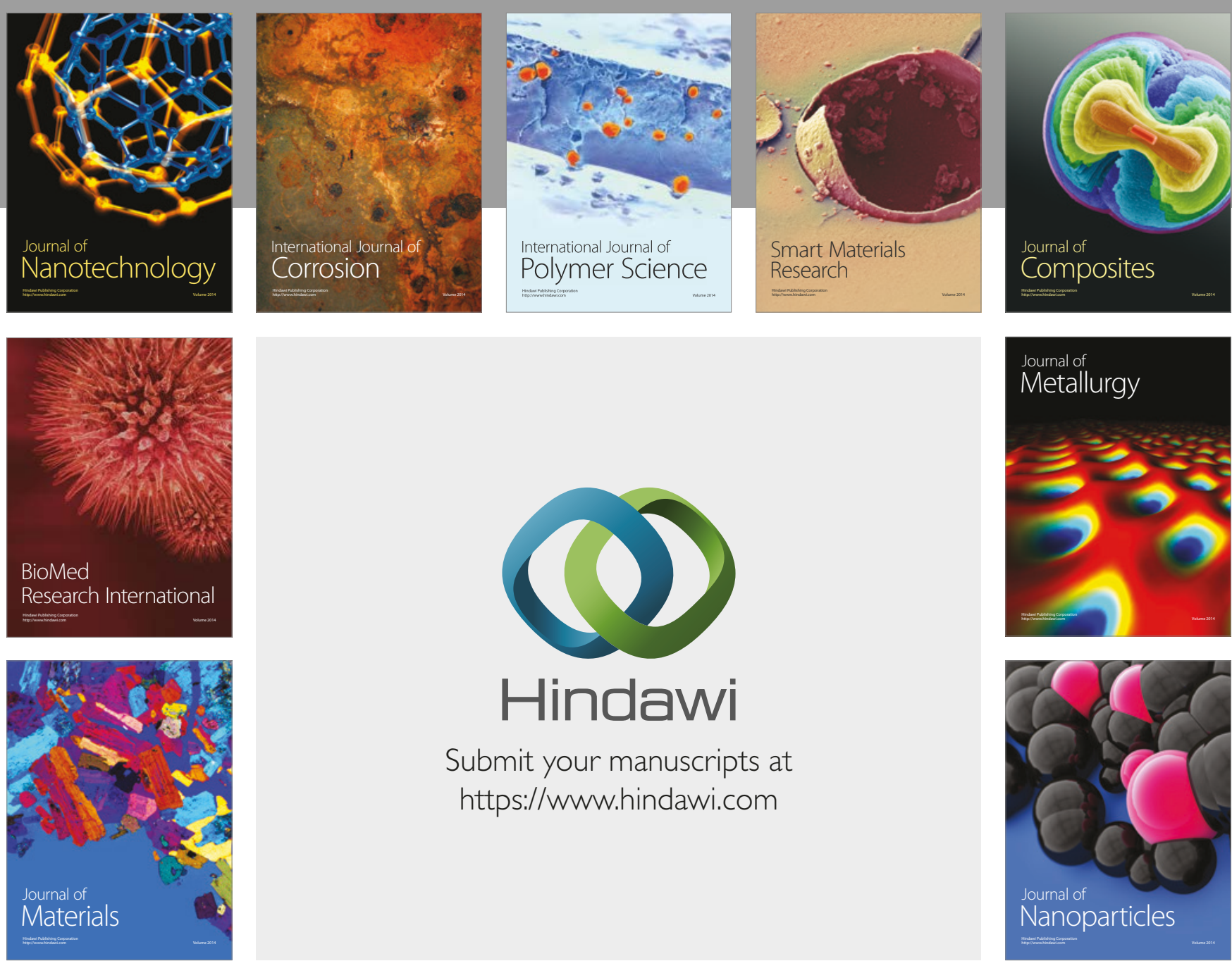

\section{Hindawi}

Submit your manuscripts at

https://www.hindawi.com
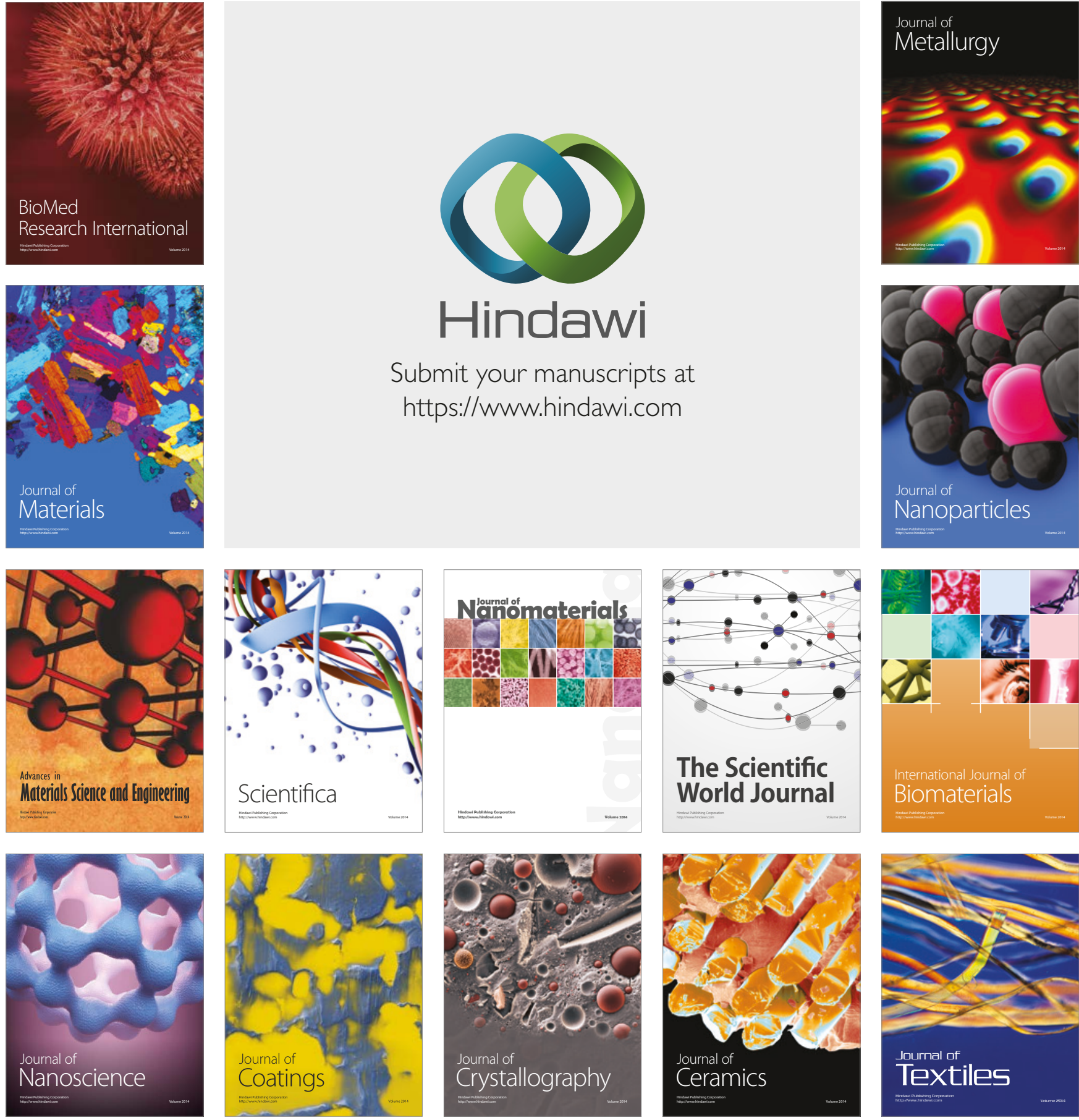

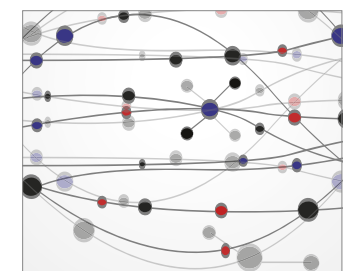

The Scientific World Journal
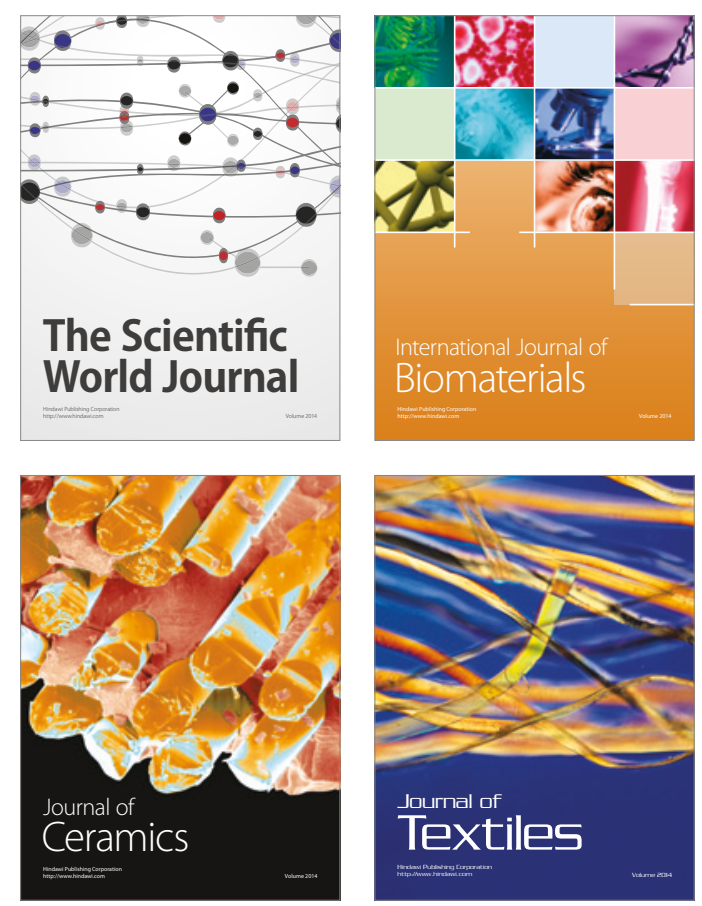